\title{
O Enegrecimento da Psicologia: Indicações para a Formação Profissional ${ }^{1}$
}

\author{
Abrahao de Oliveira Santos ${ }^{1}$ \\ ${ }^{1}$ Universidade Federal Fluminense, RJ, Brasil.
}

\begin{abstract}
Resumo: Esse texto é fruto de estudos e debates iniciados em 2012 e da possibilidade de pensar o diálogo entre a Psicologia e as práticas de cuidar na espiritualidade de matriz africana. Trazendo, no contexto da resistência negra, os valores que se apresentam nos saberes dos terreiros, acolhimento, comunidade, ancestralidade, e o lugar desses saberes ao longo da história da resistência negra no Brasil. Além de apresentar algumas referências bibliográficas, o texto se baseia nos debates com estudantes de Psicologia e nas visitas a alguns terreiros de Candomblé. O propósito do texto é indicar a importância das psicólogas e dos psicólogos entrarem em contato com alguns conhecimentos das tradições e saberes não ocidentais, presentes numa parte significativa da população brasileira. Considerando que a Psicologia e as religiões de matriz africana estão preocupadas com as questões da subjetividade, mas também com os modos de cuidar e de garantir o direito à diversidade de estilos de vida e à singularização, esse diálogo de saberes pode significar uma mudança das condições epistêmicas para a formação profissional e o trabalho da Psicologia. A perspectiva apresentada pelos saberes da população de terreiro e sua conexão com as lutas históricas do povo negro, poderiam compor na atuação, junto à população brasileira, das psicólogas e dos psicólogos. É aí que faz sentido o reclame ao enegrecimento da Psicologia. É esse sentido, com os avanços que a Psicologia pode fazer, no Brasil, que se desenvolve ao longo do texto.
\end{abstract}

Palavras-chave: Religiões de Matriz Africana, Espiritualidade, Psicologia.

\section{The Blackening of Psychology: Indications for Vocational Training}

Abstract: This text is the result of studies and discussions started in 2012 and the possibility of thinking the dialogue between Psychology and spirituality-care practices of African array. Bringing in the context of the black resistance, the values that appear in the knowledge of the terreiros meeting place, welcome, ancestry, community and the place of such knowledge throughout the history of black resistance in Brazil. Besides presenting some references, the text is based on discussions with students of Psychology and on visits to some terreiros de Candomblé. The purpose of the text is to indicate the importance of psychologists into contact with some knowledge of non-Western traditions, present in a significant part of the Brazilian population. Whereas Psychology and religions of African array are concerned with the issues of subjectivity, but also with the modes of care and to guarantee the right to diversity of lifestyles, this dialogue can mean a change of epistemic conditions for professional training and the work of psychology. The perspective presented by the knowledge of the population of terreiro and connection to the historical struggles of black people, could compose in the performance the psychologists with the Brazilian population. That is where the complaint related to the blackening of Psychology makes sense. It is in this sense, with the advances that Psychology can do in Brazil, that the text develops.

Keywords: Religions of African Array, Spirituality, Psychology.

\footnotetext{
${ }^{1}$ Este artigo baseia-se na palestra "Psicologia e Religiões de Matriz Africana: Por uma Psicologia Fora da Caixa", apresentada no X Seminário Regional de Psicologia e Direitos Humanos e IV Seminário Regional de Psicologia e Políticas Públicas, realizados pelo Conselho Regional de Psicologia do Rio de Janeiro, na UERJ, Maracanã, Rio de Janeiro, RJ, em 2015.
} 


\title{
El Ennegrecimiento de la Psicología: Indicaciones para la Formación Profesional
}

\begin{abstract}
Resumen: Este texto es fruto de estudios y debates iniciados en 2012 y de la posibilidad de pensar el diálogo entre la Psicología y las prácticas de cuidar en la espiritualidad de matriz africana. Trayendo, en el contexto de la resistencia negra, los valores que se presentan en los saberes de los terreros, acogida, comunidad, ancestralidad, y el lugar de esos saberes a lo largo de la historia de la resistencia negra en Brasil. Además de presentar algunas referencias bibliográficas, el texto se basa en los debates con estudiantes de Psicología y en las visitas a algunos terreros de Candomblé. El propósito del texto es indicar la importancia de las psicólogas y de los psicólogos para entrar en contacto con algunos conocimientos de las tradiciones y saberes no occidentales presentes en una parte significativa de la población brasileña. Considerando que la Psicología y las religiones de matriz africana están preocupadas por las cuestiones de la subjetividad, pero también con los modos de cuidar y de garantizar el derecho a la diversidad de estilos de vida y a la singularización, este diálogo de saberes puede significar un cambio de las condiciones epistémicas para la formación profesional y el trabajo de la Psicología. La perspectiva presentada por los saberes de la población de terrero y su conexión con las luchas históricas del pueblo negro, podrían componer en la actuación, junto a la población brasileña, de las psicólogas y de los psicólogos. Es ahí donde tiene sentido el reclamo al ennegrecimiento de la Psicología. Es ese sentido, con los avances que la Psicología puede hacer, en Brasil, que se desenvuelve a lo largo del texto.
\end{abstract}

Palabras clave: Religiones de Matriz Africana, Espiritualidad, Psicología.

\section{Introdução}

Em 2012, um colega e eu oferecemos a disciplina optativa Exu na Rua: Psicologia e pensamento ioruba, no curso de Psicologia da Universidade Federal Fluminense (UFF), Niterói. Deviso a isso envidei estudos sobre das práticas de cuidar nas religiões de matriz africana, dos voduns, inquinces, orixás, caboclos e entidades.

Também tomei conhecimento das Leis $\mathrm{n}^{\circ}$ $10.639 / 2003$ e $^{\circ} 11.645 / 2008$, sobre o ensino de história e cultura africana, afro-brasileira e indígena, na Educação Básica. O texto básico da disciplina era a Mitologia dos Orixás, de Prandi (2001), e O Candomblé da Bahia, de Bastide (2001). Com o trabalho de campo nos terreiros de Candomblé, as leituras na Antropologia e as conversas em sala de aula, aquilo que começou como uma "brincadeira" pedagógica, abriu questionamentos na formação em Psicologia e desdobrou-se em meu reencontro com a temática racial.

O que apresento nesse texto são resultados desse percurso de estudos e debates em torno da formação de psicólogos e do diálogo entre a Psicologia e as práticas de cuidar na espiritualidade de matriz africana. O texto traz o contexto da resistência negra, no Bra- sil, e os valores e saberes dos terreiros: acolhimento, comunidade, ancestralidade, cuidar. Ao trazer alguns conhecimentos desses saberes não ocidentais, este texto se propõe a pensar a possibilidade de enegrecer a Psicologia.

\section{Fundamentação teórica}

O sociólogo Roger Bastide percebeu que na luta política dos negros aqui no Brasil, não apenas "a religião Africana tem lugar de destaque” (Bastide, 1985, pp. 138-139), como a mulher negra também. Um pai de santo de Nova Iguaçu, na Baixada Fluminense, me disse, certa vez: "o forte da comunidade de terreiro é a mulher". Ao dizer isto, ele está fazendo referência e deferência, às mulheres negras e, também a um encantamento (ou inquice) chamado Ndandalunda. No Candombé, Ndandalunda é a água doce, a fertilidade, a fresca para o corpo e o espírito. Há estudo de Bernardo (2005), dizendo que foram as mulheres negras que reconstruíram no Brasil a crença nos encantamentos e os rituais do Candomblé.

Ndandalunda pode ser um termo novo para os leitores acostumados à linguagem dos povos africanos de cultura ioruba, provenientes do oeste da África 
(Kolá, 2005), também chamados de Nagôs, que chegaram ao Brasil no século VXIII. Ou também o povo dos terreiros de Candomblé Keto-Nagô. Ndandalunda é o nome da energia da água doce, das cachoeiras, da sedução feminina, da fertilidade. Ndandalunda é então a mulher guerreira que cuida dos seus filhos com amorosidade ancestral que pulsa em todas as mulheres e mães de todos os viventes, proveniente dos antepassados bantos. Os povos falantes bantos foram trazidos em maior número, entre os escravizados, para o Brasil. Segundo Yeda Pessoa de Castro, $75 \%$ dos negros escravizados eram provenientes do mundo banto-falante (Melo, 2014), vindos, sobretudo, de territórios onde hoje estão Angola e os dois Congos. Kátia M. de Queiroz Mattoso confirma que esses territórios foram "a maior reserva de homens negros para o tráfico brasileiro” (Mattoso, 2016, p. 50). Nomes como Candomblé, Umbanda, Samba, Zumbi e Inquice vêm das línguas africanas do troco banto, como Kibundo, Umbundo, Kikongo (Castro, 2005). Inquice, Voduns, Orixás, Encantados, Caboclos e Entidades são nomeações das forças cósmicas da natureza, nas distintas culturas africanas e indígenas. Nesse texto, nos referenciamos predominantemente aos saberes preservados nos terreiros de tradição angoleira.

\section{Saberes tradicionais, acolhimento e resistência negra}

De acordo com a opinião de Gomberg "os terreiros de candomblé, roças e barracões são historicamente constituídos como espaços de resistência para a manutenção dos saberes tradicionais das religiosas negro-africanas, assim como se mostram espaços propícios para a luta contra diversas formas de discriminação" (Gomberg, 2011, p. 71), sofridas pelos negros na sociedade brasileira. Eram espaços de ajuda mútua, de superação de problemas de ordem material, de difusão de conhecimento sobre a saúde da população negra e seus direitos civis. Os terreiros são espaços de acolhimento, que é algo indispensável na promoção da saúde física e mental. Augras (2008) se dá conta da potencialidade dos terreiros para a saúde psíquica, sabe do acolhimento que dispensam à população da periferia, mas só enfoca a atenção individualizada e não percebe a importância do aspecto mais coletivo do acolhimento. Os terreiros são espaços de acolhimento, que é algo indispensável na promoção da saúde física e mental. Ser acolhido como são todos os humanos pelos braços e cuidados de Kayala, a força das águas do mar. Kayala que é a mãe ancestral, por excelência, nos terreiros bantos. $\mathrm{O}$ acolhimento no terreiro: "sentir-se parte de um grupo através de atividades litúrgicas e sociais concede ao indivíduo de origem negra sentimentos de pertença, de autoestima que [...] atualizam a memória e a identidade social através de suas percepções" (Gomberg, 2011, p. 79), através da dança, dos cantos, das comidas de santo e da rede de relações estabelecidas no espaço ritual. "Uma pessoa entra pela porta do barracão e não tem nada, quando sai ela tem ancestralidade, avós, tios e mãe de santo, inúmeros irmãos e irmãs e tem toda uma memória recuperada", disse-me outro dia mãe Muagi² ${ }^{2}$ do terreiro Tumba Junsara, de Salvador.

Ancestralidade é memória e sentido do pertencimento cósmico e comunitário. Conta a lenda que antes dos negros atravessarem o Atlântico passavam um número de vezes em volta da árvore do esquecimento. Os povos europeus colonizadores que capturavam os africanos quiseram que estes esquecessem sua cultura, seu país, seu jeito de ser, sua religião, sua família, sua língua, sua comunidade e até sua humanidade. Procediam assim à colonização da memória e à animalização dos homens e mulheres africanos e, posteriormente, de seus descendentes capturados e sequestrados; quis apagar sua memória para lhe fazer sentir-se coisa nenhuma, objeto, escravo (Bona, 2016).

O acolhimento atualiza o cuidar trazido pelos saberes da ancestralidade, tais como são transmitidos pela oralidade no terreiro angola-congo. Acolher é trazer para um espaço de pertencimento do corpo e do espírito. Acolher, nesse sentido, tem efeitos de cura, de equilíbrio do corpoespírito, de retomada da memória, uma vez que é trazer a pessoa necessitada para mais próximo da Terra, ou dos inquices. Corpoespírito é a mutuê, cabeça, divindade individual, cuidada com banhos de ervas e alimentada com folhas, grãos, mel, carnes, azeite, para que a pessoa ou mutuê se fortaleça: mutuê, ngi ambate ku kiriri kiuaba (cabeça, leve-me para o bom lugar). O termo corpoespírito poderia expressar essa composição, que nas religiões de matriz africana, é inseparável, uma vez que a alimentamos com as mesmas comidas dos santos. Estamos na busca de uma palavra que retome essa conjunção

\footnotetext{
${ }^{2}$ Conversa no Lumyjacarê Junsara, Nova Iguaçu, Baixada Fluminense. Diário de campo, 8 de outubro de 2015.
} 
matéria-espírito, separada desde o platonismo; corpoespírito é palavra provisória.

Makota Valdina nos diz que a terra, conforme a filosofia dos bantos nos ensina, "é futu de nkisi de akanga Kalunga mujang jamole" (Pinto, 2014): pacotes de inquice, as energias espirituais que são os remédios deixados por Kalunga, a primeira semente de energia viva que tudo gerou no nosso planeta, que é a casa comum de todos nós, seres humanos. Pacote espiritual de energias equivalentes aos orixás e aos voduns. Em kikongo, kinsa quer dizer cuidar, curar, tomar conta. A cura, como nos dá o sentido da nossa ancestralidade, é produção de coletivo, de pertencimento, de memória não colonizada, como nos ensina o candomblé angoleiro. No culto dos inquices, voduns e orixás aprendemos a cuidar de nós mesmos e a cuidar do outro. Esse ensinamento foi crucial para que os negros e negras trazidos à força e escravizados(as) no Brasil escapassem ao destino que lhes foi reservado pelos colonizadores depois de terem acumulado toda a riqueza que os europeus necessitavam para seu próprio desenvolvimento, à custa dos povos africanos.

\section{Religião de resistência e espiritualidade do cuidar}

A ênfase no cuidar, no acolhimento, no olhar para a vulnerabilidade das pessoas, não nos coloca diante de uma religião, da pregação, da fé e da obediência, mas nos evoca o que Kola Abimbola (2005) entende como crenças relígio-filosóficas ou crenças práticas. Crenças estas compartilhadas nos terreiros, pelas quais os povos da diáspora africana guiam e regulam condutas e governam suas vidas. Nos anos 1950, o antropólogo Roger Bastide considerou o Candomblé como uma religião de resistência e não como "ópio do povo" (Bastide, 1985, p. 9), conforme tinha a visão marxista. Na religião de resistência, o antropólogo-sociólogo francês percebia uma "epistemologia afro-brasileira", uma "concepção alargada do ser", uma "filosofia e uma concepção do homem" (Bastide, 1985, p. 24), preservada pelas empregadas domésticas, lavadeiras, operárias e pequenos comerciantes, mulheres e homens da periferia social, que em sua época ainda não havia sido devidamente pesquisada. Filosofia e ontologia dos povos africanos foram descritas há muito tempo (Kagame, 1975; Templs, 1948). Quando esse conhecimento chegou a mim, vi começar a enegrecer toda a minha visão de Psicologia. Por ignorar e negar as lutas para existir, dos grupos não brancos e seus saberes, a Psicologia e demais campos profissionais, no Brasil, sofrem de terrível defasagem conceitual da formação profissional, conforme começam a mostram as pesquisas na Psicologia (Oliveira, 2017).

Essas práticas de cuidar de si e do outro, no sentido não da sujeição, mas da subjetivação não sujeitada, entraram na pesquisa de Foucault (2006) no lugar de espiritualidade. Entretanto, diferentemente do cuidado de si dos gregos e romanos do período clássico, a espiritualidade no Candomblé não se volta para o "acesso à verdade" (Foucault, 2006, p. 12), mas para a criação de tipos específicos de pessoas, como mostra em detalhes a pesquisa dos "processos de singularização" nas religiões de matriz africana, de Opipari (2009, p. 197). O processo de constituição da pessoa é regido pelas forças cósmicas da natureza, os inquices (Abimbola, 1981; Goldman, 1985; Bâ, 1981;), é, portanto, acêntrico e regido pelo próprio indivíduo, como seria numa concepção ocidental.

\section{Perspectiva afropindorâmica, memória ancestralidade, comunidade}

A retomada da memória dos modos de cuidar de homens e mulheres negros e negras, na diáspora que hoje se observa em qualquer terreiro, tem sido muito importante para a conquista de direitos sociais e o enfrentamento do racismo e dos seus efeitos na população negra. A principal doença que temos que curar é o racismo que pesa de geração a geração "por conta das condições em que nós fomos trazidos, das condições em que nos foram impostas pela escravidão" (Pinto, 2014). Mas essa doença, conforme Valdina Pinto, não conseguiu destruir completamente nossos saberes, porque ainda mantemos a memória dos jeitos de viver.

O Candomblé é um espaço privilegiado de retomada da memória, do afeto de pertencimento histórico, de relações sociais recuperadas. É importantíssima pra todos os brasileiros a memória desse modo de entender o cuidado, como esse jeito que fortalece o laço coletivo e a conexão das pessoas com a natureza. A Terra, o Mar, o Fogo, o Vento, a Mata (Renafro, 2013), o Trabalho, o Caminho, o Encontro, o Acolher, a Brincadeira, o Saber, o Tempo. Tudo isso aí que vem antes das mulheres e dos homens é ancestral das mulheres e dos homens, são os inquices tais como são nomeados nos terreiros angola. Essa perspectiva, moldada em solo brasileiro com a ajuda dos Caboclos ou dos povos 
indígenas, a qual poderíamos chamar de afroindígena ou afropindorâmica, toma como universal uma ética do cuidar e do acolhimento (Renafro, 2013), da atenção à vulnerabilidade do outro. Afropindorâmica é o termo dado por Santos (2015) aos povos da resistência contracolonal brasileira. Ou como apareceu na etnografia de Cecília Mello, o modo de "reaproveitamento" ou "ressuscitamento" (Mello, 2003, p. 94) de materiais do lixo, com a qual se pode fazer artesanato, mas também o modo como podemos narrar nossa história, a história do país e nosso engajamento político, modo "do que se transforma em outra coisa diferente do que se era e que, de algum modo, conserva uma memória do que se foi" (Mello, 2003, p. 95). Afroindígena, sem hífen, é como Goldman (2015, p. 642) designa, não a junção dos modos distintos dos dois grupos sociais, mas conota a operação de composição de resistência dos povos indígenas e afrodiaspóricos.

Entre os povos indígenas e os negros há mais que a condição de insurgência de dois grupos, há a valorização da ancestralidade, da coletividade, da ontologia da coalescência matéria e espírito, na qual a existência está ligada à comunidade e à terra (Akiwowo, 1986). Voltar-se para os processos de transformação da existência (Kagame , 1975) e pôr a espiritualidade e o cuidar da vulnerabilidade no coração da moral, torna-nos parceiro da luta internacional pela construção de uma sociedade inclusiva (Anônimo, 2017).

Em 2014 visitei o terreiro Tombenci Neto, em Ilhéus, no interior da Bahia, com um axé de mais de 100 anos; e a Nzo Sitamba, em Igarassu, na Grande Recife. Fiquei 15 dias em cada um deles, comendo junto com a comunidade do terreiro, ouvindo as histórias sentado nas esteiras feitas da tabua das varges, num reencontro com elementos da minha infância. Também ouvi história a respeito dos embates que as comunidades estão passando, dos terríveis problemas do racismo religioso. Conheci também o Terreiro Tumba Junsara, em Salvador, que agora faz 100 anos. Dessas visitas e dos encontros nacionais e regionais realizados pela Rede Nacional de Religiões de Matriz Africana e Saúde (Renafro), de que tenho participado, parece-me notório que o povo de santo está tomando noção de sua condição social e histórica como agente político e como um grupo que faz política pública de saúde, que tem discurso próprio sobre si e uma con- cepção própria do que é saúde e das técnicas de fazer saúde. No X Seminário Nacional das Religiões Afro-Brasileiras e Saúde e I Encontro das Mulheres de Axé de Ilhéus, promovidos pela Renafro, em 2015, Lúcia Xavier, filha de mãe Beata de Iemanjá, na cidade de Nova Iguaçu, entende que não somente:

Criamos espaços de acolhimento que são os terreiros, mas também nos enraizamos, constituímos tradição, nos constituímos como um grupo que lutou e fala por si, fala da nossa condição humana, fala da nossa perspectiva [...] Nós dos cultos de matriz africana emprestamos esse legado de luta, resistência e construção para toda a população negra de modo geral, mesmo as pessoas que não são de terreiro, para que se inspirassem na luta contra o racismo e seus efeitos. Essas tradições nos empoderaram, nos colocaram nesse mundo de outra forma. Esse enraizamento ajudou a construir nossa egbé, essa comunidade, esse modo coletivo de viver, esse modo coletivo de agir ${ }^{3}$.

É da resistência e da militância de homens e mulheres negros e negras que tenho escutado esse chamado para o enegrecimento, do qual tento aqui trazer um sentido epistêmico.

\section{O tratamento coletivo de nós mesmos}

Makota Valdina entende que, nesses encontros e seminários que reúnem o povo de santo para falar de si mesmo, de suas necessidades, de seus problemas, para dançar e cantar, estamos nos reconhecendo e aprendendo uma nova experiência, um novo jeito de conversar que ainda está no começo, mas que são avanços importantes no processo de autocura. Estamos fazendo esse tratamento das relações, como fazemos no terreiro, quando estamos juntos na feitura do santo, na aprendizagem cotidiana de louvar o inquice, de oferecer comida, fazer a festa onde toda a comunidade é servida, de arrumar o terreiro, de ratear as despesas comunitariamente. Estamos nos curando coletivamente e nos fazendo e refazendo de modo diferente.

Nos eventos de Ilhéus, em 2014, a professora e ativista negra Makota Valdina, do Terreiro Tanuri

\footnotetext{
${ }^{3}$ Lúcia Xavier, em palestra no X Seminário das Religiões Afro-Brasileiras e Saúde: Cultura, práticas de cuidado e políticas públicas, Ilhéus, 2015.
} 
Junsara, em Salvador, disse que "a doença que o racismo impõe a gente é a pior doença". O racismo como estratégia de dominação, na África, na Europa, nas Américas, na Ásia. O racismo orquestrado pelos europeus e do qual os franceses, belgas, alemães, ingleses, holandeses, dinamarqueses e demais povos europeus, são os que se beneficiaram e se beneficiam dele (Moore, 2010). Nos encontros da Renafro, estamos conhecendo a riqueza de cultos ao sagrado que há no Brasil: o Candomblé Angola, Keto, Jeje, a Jurema, a Umbanda. Estamos dando-nos conta da importância disso; fortalecendo-nos no axé, no ngunzo, na energia espiritual que está em tudo que existe (Santos, 1998); do trabalho de cura e tratamento coletivo de nós mesmos. Porque, para o povo de terreiro, o coletivo e a multiplicidade são a condição de sua força de vida, o nguzo, o axé.

\section{Energia corpoespiritual e enegrecimento}

O que é essa energia espiritual? Nguzo, para os terreiros angola-congo; axé, nos terreiros keto-nagô; ou o princípio universal asuwa, na Nigéria; a fonte de todas as coisas, é desenvolvido pela comunidade e jamais por um indivíduo sozinho (Akiwowo, 1986). Recentemente meu pai de santo tata Luazemi Roberto Braga me disse: "o Candomblé é energia pura, filho". "O que é essa energia, meu pai?" aproveitei a oportunidade e perguntei. E ele: "olhe isso aí em volta, a energia das folhas, da água, do bori" 4 . Surpreendi-me, pois esperei a explicação de uma energia transcendente, impalpável. A energia espiritual, segundo tata Luazemi, encontra-se na seiva e no cheiro das folhas, na natureza, na água que vem da terra. Em qual saber Nietzsche teria se inspirado quando falava do "sentido da terra" e conclamava para que "permaneçamos fiéis à terra" (Nietzsche, 1995, § 3)? A espiritualidade no Candomblé é natureza, é coalescência do corpo e do espírito, energia corpoespiritual. Vejam Kavungo (Figura), por exemplo, que é a terra, a energia da terra, a força que está nas folhas, a energia que nutre, nos mantem vivos e transforma a doença em cura. Mas é natureza também a justiça, a sedução, a negociação, o encontro, tudo é dom da natureza, pois natureza e cultura são inseparáveis.

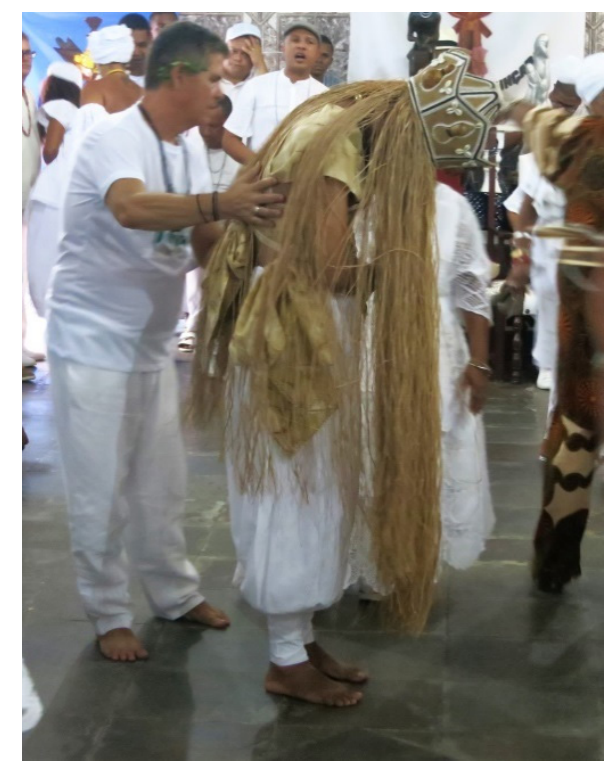

Fonte: Arquivo pessoal.

Figura

Kavungo dança entre os filhos.

Essa energia, como ela se desenvolve? Tem uma entidade que é das mais consideradas no culto banto à natureza que é Njila, o princípio de tudo que existe, a abertura ou caminho para o encontro, a encruzilhada, o propulsor dos acontecimentos (Santos, 1998). Njila é também o circuito de comunicação, o que faz circular as trocas entre os vários campos de energia de constituição da pessoa. Por que o Encontro, a Encruzilhada, a Comunicação são tão importantes? Porque sem isso não haverá comunidade nenhuma. Não haverá egbé, não haverá terreiro. Não haverá como equilibrar os interesses e as diferenças, que anto o povo de santo valoriza, portanto, não se farão negociações nem acordos nem trocas. Acordos são fundamentais para o equilíbrio da pessoa, para a saúde, para a própria existência da comunidade, para a troca entre as pessoas e a troca com as forças da natureza, os ancestrais. Tudo precisa de acordo, sem o qual não dá para aumentar o nguzo; sem acordo não dá para lutar e resistir. É a comunidade que produz o nguzo ou axé que é o "poder de realização" (Santos, 1998, p. 46). Então, quando o povo de santo define saúde como equilíbrio espiritual, também coloca a saúde como produção da força da comunidade. A convivência no terreiro nos faz ver que o maior trabalho dos adeptos do Candomblé é a manutenção e o fortalecimento da

${ }^{4}$ Anotação no diário de campo, 30 de outubro de 2015. 
comunidade. Aqui está o princípio do enegrecimento para o profissional da Psicologia que vai cuidar da população brasileira. Digo enegrecimento, em vez de esclarecimento, em favor de um saber, ou razão, que não se coloca como universal nem do extermínio de outros saberes. Enegrecer é adotar o conhecimento da ancestralidade, a intuição de Njila, a disposição para a troca, a comunicação, o acordo comunitário que envolve as pessoas e os ancestrais.

\section{Do despertencimento à busca do equilíbrio espiritual}

O sociólogo alemão Elias (1994) alerta para as "ciências que tratam o indivíduo singular como algo que pode ser isolado e que busca elucidar a estrutura de suas funções psicológicas independentemente de suas relações com as demais pessoas" (Elias, 1994, p. 15). O que muitas vezes chamamos autonomia, pelos profissionais da atenção à saúde mental, por exemplo, não é senão a capacidade da pessoa agir isoladamente. O Psiquiatra francês Nathan denuncia que as psicoterapias científicas ou modernas (a psicopatologia, a psiquiatria) produzem o "isolamento deliberado dos pacientes" (Nathan, 1995, p. 13), produzem desvinculação do paciente dos seus semelhantes, o que nós dos movimentos negros poderíamos chamar de despertencimento. Da forma social do isolamento, Nobert Elias identifica a produção de "angústia" e "vazio existencial" (Elias, 1994, p. 103), de onde surgem inúmeras modulações do sofrimento psíquico, como depressão, pânico, doenças psicossomáticas, desesperança, alcoolismo.

Silva (2017) e Jesus, Silva e Carmo (2018) valorizam a experiência local da disciplina de 2012, integrada como matéria obrigatória no Projeto Político Pedagógico do Curso de Psicologia (PPPC), em 2013, sob a coordenação do professor André do Eirado, com o nome de Sociedade Brasileira e África: subjetivações afrodescendentes, ao indicar as repercussões na formação profissional. Nesta disciplina e em eventos, palestras e encontros acadêmicos, alguns realizados pelos próprios estudantes do curso, os formandos de Psicologia entram em contato com a história da resistência negra e as práticas de cuidar das religiões de matriz africana. Além de cultuar o sagrado, há nos terreiros práticas de cuidar e uma filosofia de vida de altíssimo valor, bloqueadas pelo racismo, as quais a Psicologia ainda desconhece. É sabido que "a Psicologia brasileira posicionou-se como cúmplice do racismo, tendo produzido conhecimento que o legitimasse, validando cientificamente estereótipos infundados por meio de teorias eurocêntricas discriminatórias, inclusive por tomar por padrão uma realidade que não contempla a diversidade brasileira" (CFP, 2017, p. 75). A avaliação de que "hoje em dia, a Psicologia mantém-se ainda conivente com a perpetuação desse olhar" (CFP, 2017, p. 76), pode significar uma mudança na formação profissional. Quando, em 2002, a Comissão Nacional de Direitos Humanos lança a campanha $O$ Preconceito Racial Humilha, A Humilhação Social Faz Sofrer (CFP, 2017) e o Conselho Federal de Psicologia (CFP) publica a Resolução $\mathrm{n}^{\circ} 18 / 2002$, que estabelece normas de atuação para as(os) psicólogas(os) em relação ao preconceito e à discriminação racial, temos, na nossa categoria, o compromisso da formação do psicólogo sensível às questões dos grupos socais não brancos (negros e indígenas).

É necessário que as psicólogas e os psicólogos conheçam a história da diáspora africana no Brasil e compreendam as práticas de cuidar das matrizes culturais e civilizatórias presentes na população. Nós psicólogos precisamos buscar, nas práticas diaspóricas, inspiração para o cuidar das pessoas no Sistema Único de Saúde (SUS), nos consultórios, na rede escolar, nas comunidades e no campo do trabalho.

Não devemos desconsiderar que, "de acordo com o Instituto de Pesquisa Econômica Aplicada (Ipea), em 2008, a população negra representava $67 \%$ do público total atendido pelo SUS” (Brasil, 2017, p. 13). O SUS é o plano de saúde da população negra. Precisamos urgentemente pensar nas especificidades que envolvem o sofrimento psíquico dessa população, mas não apenas em suas carências e necessidades, senão também nos recursos culturais e civilizatórios que ela porta. Um estudo exploratório identificou que, para os psicólogos, saúde mental é equilíbrio de vida e capacidade para mudança e experimentações (Oliveira, \& Junges, 2012). Na valorização dos profissionais da nossa categoria se afirmam esses saberes da espiritualidade e da religiosidade de matriz africana e indígena, que agora estão saindo da invisibilidade. Não obstante, dentro da Psicologia, ainda não temos um conceito de equilíbrio como ferramenta para nossas práticas. A categoria equilíbrio é recorrente nos entrevistados de Gomberg (2011), em sua pesquisa sobre encontros terapêuticos nos terreiros de candomblé. O equilíbrio corpoespiritual é alcançado com as trocas de energia com os ancestrais, 
inquices, orixás, voduns, caboclos e entidades, dissemos acima. Restabelecido o equilíbrio, a pessoa recebe força do inquice e tem o saber de conduzir sua vida conforme aquilo mesmo que necessita para se realizar, fazer mudanças e experimentações, como intuem os Psicólogos (Oliveira, \& Junges, 2012).

Em "Sociedade Brasileira e África: subjetivações afrodescendentes", tenho batido na tecla da importância das religiões de matriz africana na cultura brasileira; tenho batido na tecla de que os intelectuais, os professores de Psicologia e as psicólogas e os psicólogos precisam conhecer as práticas de cuidar das religiões de matriz africana, que trazem um riquíssimo acervo quanto aos modos de cuidar das pessoas e da cidade e um novo modo de conceber a existência.

\section{Uma clínica do território e o terreiro}

Em tudo que falei acima, do Candomblé e os fóruns de debate, tenho sido redundante na ênfase da importância da reconstrução ou construção do aspecto comunitário no processo de cura, de tratamento, de cuidar das pessoas, a partir dessa visada epistêmica que experimento chamar de enegrecimento. No projeto de estágio do Curso de Psicologia da UFF na rede de saúde mental de Niterói, propus a intervenção junto aos usuários com diagnósticos de transtornos mentais severos, no Centro de Convivência e na Residência Terapêutica, dois serviços da Rede de Atenção Psicossocial (RAPS), uma atenção voltada para a circulação na cidade, algo que se aproxima da proposta de Antonio Lancetti de clínica peripatética (Lancetti, 2006), mas com diferenças. Uma proposta, vale lembrar, inteiramente conforme os princípios da atenção psicossocial da Reforma Psiquiátrica brasileira. Como não fazíamos uso dos conceitos da Psicanálise, como interpretação e transferência, ou seja, como não considerávamos a relação sujeito - objeto, como não considerávamos a base psicanalítica da relação analista - paciente, tivemos muita resistência dos psicólogos das equipes da RAPS, quanto à proposta de cuidado, do estágio curricular do curso de Psicologia. Para responder à dificuldade aí colocada, formulamos a noção de Clínica do Território, na qual passamos a cuidar do ambiente, das relações, da construção de uma rede comunitária do usuário.
Eram os saberes de matriz africana, provenientes da vivência nos terreiros de Candomblé e dos estudos, que me inspiravam, na direção daquilo que a Reforma preconizava em termos de desinstitucionalização.

A clínica do território vem dos afetos que me chegaram no encontro com o povo de terreiro; vem da recuperação de uma memória, da experiência com as brincadeiras de roda no terreiro; meu legado de descendência indígena e africana, no sudoeste baiano, na região cacaueira, onde nasci e cresci até meus 10 anos. Na minha infância, chamávamos o espaço aberto e público em frente das nossas casas de terreiro. As crianças brincando de pega-pega, de cantigas de roda, o encontro com as histórias da carochinha contada pelos adultos. Tinha a festa de Cosme-Damião que reunia amigos e uma multidão desconhecida para comer, beber, dançar, festejar a vida e os santos, o mundo sagrado das forças, e mais que tudo, praticar a comunidade e a reunião. Lembro-me também do ajunte, mutirão para terminar a casa do trabalhador, que se dava com dança, música, e fogos de artifício, de modo que o trabalho conforme os valores vindos dos legados africanos ou indígenas, não se configurava como castigo. Terreiro, roça ou barracão chama-se também o espaço no qual realizamos as trocas com as forças cósmicas da natureza, os inquices, caboclos, orixás e voduns, e buscamos o equilíbrio espiritual, a saúde e a alegria de viver.

Com esse projeto na rede de saúde mental em Niterói e depois o encontro com as práticas de cuidar nos terreiros, as coisas se juntaram. Ora, na tradição africana, o trabalho espiritual pretende "construir contextos favoráveis e desfavoráveis se comunicando e dialogando com as diversas instâncias da sociedade" (Gomberg, 2011, p. 47). As danças, os cantos, os tambores, as comidas, as oferendas aos santos, a reunião da comunidade é o meio de produzir o nguzo, a força propulsora da existência e do desenvolvimento (Santos, 1998), é a força de equilíbrio espiritual e, portanto, de produzir saúde. Como relata mãe Arlene de Katendê ${ }^{5}$ o trabalho de cura deve tornar favoráveis as energias que se encontram nas folhas, no mar, na cachoeira, na rua, na praça, no sentido de justiça, a fé num novo futuro e na transformação das coisas. Produção de sinergia dos heterogêneos.

${ }^{5}$ Comunicação feita no Kitembo Laboratório de Estudos da Subjetividade e Cultura Afro-Brasileira, em reunião no Campus Gragoatá, UFF, no dia 12 de junho 2013. 


\section{Psicologia, contexto social: do individual ao coletivo}

Simone Lahud Guedes percebe nas práticas de cuidar da Umbanda, que todo problema situado na mente individual, envolve a relação social. Primeiro, devido à perturbação de eguns e Exus; depois, em decorrência de relações sociais ruins. Então, a lição que devemos aprender aqui com os mestres da Umbanda e do Candomblé é que o comportamento chamado "anormal", as doenças, o sofrimento do corpo e do espírito, que a Psicologia vai entender estar no indivíduo, envolve uma "perturbação" (Guedes, 2003, p. 97) de forças vindas de fora. Seguindo Guedes, a Umbanda, assim como a Psicologia, está preocupada com o mesmo problema do comportamento normal, desviante ou doentio, considerando os devidos e diferenciados enfoques. Essa posição acompanha os Conselhos Regionais e Federal de Psicologia. Segundo nossas entidades de classe, e apresentando termos mais afeitos à nossa linguagem, "tanto a religião quanto a Psicologia transitam num campo comum, ou seja, o da produção de subjetividades" (CRP-SP, 2014). O antropólogo Gilberto Velho diz que dentro da Umbanda há uma teoria da doença ou do desvio com base na "identificação de perturbações na rede de relações sociais perturbadas e poluídas" (Velho, 1997, p. 103). Decorre daí que o problema precisa ser solucionado a partir de intervenção que vai refazer o sentido dessas relações, pois, "não são as pessoas que estão erradas [...] e sim a rede de relações que abarca esses indivíduos" (Velho, 1997, p. 103). $\mathrm{Ou}$, seja, desse ponto de vista da Umbanda, a intervenção de cuidado deve visar não o indivíduo isolado, mas a rede. É na rede que o indivíduo pode alcançar o equilíbrio necessário à sua saúde. Daí enfatizar a perspectiva acêntrica do cuidar, na qual começamos pela queixa do indivíduo, porém, a intervenção será no meio ambiente. A rede, no caso do Candomblé, da Umbanda e dos saberes indígenas, envolve não apenas redes sociais, mas também as relações do indivíduo com os mortos e com as forças cósmicas da natureza, portanto, a rede integra uma vasta malha de relações de pertencimento. Como bem concebe o povo de santo, a unidade básica da vida não se restringe ao indivíduo biológico ou psicológico, mas às redes relacionais que conformam o indivíduo. A Psicologia Social já nos diz que "toda expressão psicológica é uma produção de sentido associada a uma configuração pessoal que tem uma história e um contexto"
(Rey, 2004, p. 144). Portanto, o conhecimento que trazemos da espiritualidade dos saberes tradicionais não é uma estrita novidade para o psicólogo. Todavia, na hora de intervir, muitas vezes o profissional esquece-se do contexto e da trama de constituição do indivíduo e volta-se para a pessoa e seus problemas isoladamente, atendendo assim não apenas às necessidades de atenção de alguém, mas ao preceito normativo da sociedade individualizante de que falava Elias (1994). Na formação profissional o elemento da memória, da rede comunitária e do enraizamento dos grupos com os quais o psicólogo vai trabalhar talvez não estejam bem desenvolvidos, como ferramentas de trabalho. O umbandista orienta-se também, em sua prática de cura espiritual, com uma noção de pessoa própria, semelhante àquela dos candomblecistas de que falam Abimbola (1981), Bâ (1981) e Goldman (1985).

Em sua clínica nos arredores de Paris, atendendo às famílias que vieram da África, o psiquiatra e psicanalista Nathan (1995) adota a mesma direção que apresentamos acima: as terapêuticas operadas pelos "mestres do saber oculto", como mães e pais de santo, se deslocam "do individual para o coletivo" (Nathan, 1995, p. 18). A abordagem de Tobie Nathan, acêntrica e também, como apresentamos na perspectiva local acima apresentada pelas práticas de cuidar afropidorâmicas, age procurando os problemas relacionais e históricos, age procurando a questão do pertencimento à comunidade incluindo vivos e mortos, humanos e não humanos. Para esse psiquiatra a psicoterapia deve, no tratamento das doenças, refazer ou fazer os realinhamentos dos indivíduos com suas tradições, suas famílias, suas etnias, suas lutas sociais, a condição social na qual o indivíduo se encontra.

Mas esse não é exatamente o sentido dos encontros que descrevemos acima, dos seminários, das práticas de terreiro, da perspectiva do enegrecimento? A gente está se recriando, a gente está se curando, no sentido do que se faz na roça, no sentido de acolher um ao outro, no sentido de recuperar a memória e a luta ancestral. No encontro com o sagrado praticamos a memória, desenvolvemos a comunidade, elaboramos e fortalecemos os laços sociais e os laços dos homens e mulheres com a terra, com o mundo, com a natureza. A formação do nguzo que se dá no encontro, nos seminários da Renafro, nas festas do Candomblé, nos vários grupos de resistência social da população negra e dos povos indígenas, nos traz vitalidade, equilíbrio, saúde, sentimento de pertenci- 
mento e força para lutar. O psiquiatra e psicanalista martinicano Frantz Fanon questiona, em 1952, o uso das teorias de Freud e dos pós-freudianos para a comunidade negra que se vê adoecida de problemas psicológicos. Não basta resolver o problema de um e de outro isoladamente, mas "agir no sentido de uma mudança das estruturas sociais” (Fanon, 2008, p. 95). O trabalho psicoterápico deve levar o negro, não a se adequar à sociedade branca, mas deve levá-lo a se tornar capaz de encontrar novas possibilidades de existir. Ou seja, a Psicologia precisa se ocupar da existência real, dos problemas reais, e também deve compreender os recursos terapêuticos e as formas históricas do "ser negro" (Fanon, 2008, p. 104).

\section{Considerações finais}

Quero finalizar esta sucinta e inicial apresentação do importante debate que temos que fazer com os profissionais da Psicologia que vão cuidar do sofrimento psíquico da população brasileira, das demandas e adversidades de sua saúde mental ou saúde de um modo geral e demais vicissitudes. Questões decorrentes, como nos ajudam a ver o que discorremos acima, de nossa longa história de colonização, da luta pela sobrevivência, pela memória da comunidade e do sentido da ancestralidade da existência.

Considerando o que as religiões de matriz africana ensinam e a Antropologia, conforme dissemos acima, se levarmos em conta os avanços nos debates e posicionamentos de nossa própria categoria profissional, a Psicologia e as religiões de matriz africana estão preocupadas com as questões da subjetividade, da formação das pessoas. Entretanto, ambas também se preocupam com modos de cuidar e de garantir o direito à vida singular. Nesses avanços, já está estabelecido um campo comum no qual transitamos, o da produção de subjetividades, da construção da pessoa, dos direitos à diversidade e à singularização. Nosso código de Ética nisso é objetivamente explícito, quando quer assegurar, orientando-se na Declaração Universal dos Direitos Humanos, o direito à diversidade de estilos de vida da pessoa humana, o que se concretiza no direito de liberdade de convicções políticas, morais, religiosas, de orientação sexual (CFP, 2005). Tratou-se, ao longo do texto, de valorizar e afirmar a disposição de cada um realizar-se e constituir-se diferentemente, uma consonância das práticas de cuidar nas religiões de matriz africana e do nosso Código de Ética. Essa diretriz de trabalho é impres- cindível na construção de uma sociedade civilizada, no sentido da definição de civilização como aquela que cria abordagens mais inclusivas da diversidade humana, em oposição à civilização como fábrica do "normal" (Stengers, 2013, p. 128).

O texto mostrou que a população negra porta, em seu itinerário de resistência histórica, da colonização em 1500 até os dias atuais, perspectivas filosófica e ontológicas assentadas nas práticas de cuidar do povo de terreiro ou das religiões de matriz africana, em estreita conexão com a afirmação do direito a diversidade de subjetividade. Mas, além disso, a Psicologia, ao atuar com a população negra, encontra-se no mesmo campo que é o de cuidar do sofrimento da população, das angústias, do vazio existencial, dos efeitos do racismo e das doenças mentais. Só não incorporamos, até agora, de modo generalizado para a categoria, a ideia de que a principal doença que temos que curar é o racismo. Mas isso é o que está por vir. Desde 2002, a categoria mobiliza-se na direção de reconhecer a vivência social da população negra.

Diante disso, não há como não defender a inclusão da perspectiva do enegrecimento, na formação do psicólogo, se isso é tão importante para a compreensão da saúde integral da população negra. Teremos que elaborar o sentido para o que os movimentos negros vêm chamando de enegrecimento, aqui apenas indicado. Esse sentido, que trará ganhos epistêmicos, transformações nos caminhos (metodologia) de pesquisa na Psicologia, ganhos políticos em termos da superação do lugar subalterno da população negra e de construção da equidade sociorracial, deve ser construído coletivamente, pelas práticas de militância da população negra e dos parceiros antirracistas, pelos escritos dos intelectuais negros e demais parceiros da luta por equidade sociorracial. O sentido epistêmico que quero dar à perspectiva afropindorâmica ou ao enegrecimento vem da resistência, de muito tempo atrás, de homens e mulheres negros e negras; vem também da militância universitária que veio com as políticas de cotas e quer falar. Esses novos atores da intelectualidade brasileira precisam avançar mais nas pesquisas e no debate até que produzam uma boa resposta a si mesmos do sentido do enegrecimento.

A perspectiva afroindígena, afropindorâmica ou o que poderá vir a ser uma perspectiva do enegrecimento, baseia-se na necessária equilibração da vida em comunidade criada a partir de trocas e acordos, envolvendo o mundo social, os valores civilizatórios 
das tradições negras e indígenas, na indissociabilidade entre cultura e a natureza, na coalescência entre corpo e mente, no respeito aos antepassados ou à ancestralidade, numa moral do cuidado à vulnerabilidade, tal como a vemos praticada nos terreiros de Candomblé congo-angola. Poderia a Psicologia adotar a moral de cuidado da vulnerabilidade como um princípio do enegrecimento? Fica a questão.

O Candomblé nos oferece a memória, mais que uma religião, como formas de existir, de resistir, de criar o nosso dia a dia, de fazer e viver o mundo. É como diz a antropóloga Segato, "uma psicologia autêntica com uma teoria da conduta humana" (apud Opipari, 2009, p. 178), porém, de um modo que considero relevante ressaltar, que não nos leva a buscar a terapêutica de adaptação social, mas de construir relações de aliança com as forças da natureza, os orixás, nkisi, caboclos, encantados e assim construir ou fazer uma experiência própria da pessoa. Em vez da adaptação, estamos diante, nos trabalhos de cura corpoespiritual, na feitura do santo ou iniciação do adepto. Estamos também na dinâmica de formação de novos tipos de pessoa, o que na Psicologia nós podemos chamar de singularização. Os terreiros desenvolvem esse cuidar que não é reconhecida pelo sistema oficial, mas mães, pais de santo e os muzenzas (filho de santo) sabem da sua eficácia e de sua importância.

Pelo que tenho visto se agitar no trabalho de formação profissional, nas escritas de trabalhos de conclusão de curso (TCC), dissertações de mestrado, teses de doutorado e debates nos congressos científicos, talvez estejamos diante da formulação da quebra epistemológica e a invenção de novas bases da Psicologia no Brasil, baseado, finalmente, numa produção conceitual alicerçada no próprio contexto brasileiro.

\section{Referências}

Abimbola, W. A. (1981). Concepção ioruba da personalidade humana (L. L. Marins, Trad., 544a ed.). Paris: Centre National de la Recherche Scientifique.

Akiwowo, A. A. (1986). Contributions to the sociology of knowledge from an african oral poetry. Internacional sociology, 1(4), 343-358. https://doi.org/10.1177/026858098600100401

Anônimo. (2017). Faires attention les uns aux autres. Multitudes, 66(1), 45-47.https:// doi.org/10.3917/mult.066.0045 (era Multitudes.)

Augras, M. (2008). O duplo e a metamorfose: A identidade mítica em comunidade nagô. Petrópolis, RJ: Vozes.

Bâ, A. H. (1981). La notion de personne en Afrique noire. In: R. Bastide, \& G. Dieterlen (Org.), La notion de personne en Afrique noire (pp. 181-192). Paris: CNRS. (era Hampâté Bâ, A.)

Bernardo. T. (2005). O candomblé e o poder feminino. Revista de Estudos da Religião, (2), 1-21.

Bastide, R. (1985). As religiões africanas no Brasil: Contribuição a uma sociologia das interpenetrações de civilizações. São Paulo, SP: Pioneira.

Bastide, R. (2001). O candomblé da Bahia. São Paulo, SP: Companhia das Letras.

Bona, D. T. (2016). Fugitif, où cours-tu? Paris: PUF.

Brasil. Ministério da Saúde. (2017). Política nacional de saúde integral da população negra: Uma política do SUS (3a ed.). Brasília, DF: o autor.

Castro, Y. P. (2005). Falares africanos na Bahia: Um vocabulário afro-brasileiro. Rio de Janeiro, RJ: Topbooks.

Conselho Federal de Psicologia - CFP. (2005). Código de ética profissional do psicólogo. Brasília, DF: o autor. Recuperado de https://site.cfp.org.br/wp-content/uploads/2012/07/codigo-de-etica-psicologia.pdf

Conselho Federal de Psicologia - CFP. (2017). Relações raciais: Referências técnicas para atuação de psicólogas/os. Brasília, DF: o autor.

Conselho Regional de Psicologia de São Paulo - CRP-SP. (2014). Laicidade e psicologia: Posicionamento do sistema conselhos de psicologia para a questão da psicologia, religião e espiritualidade. São Paulo, SP: o autor. Recuperado de http://www.crpsp.org.br/portal/midia/fiquedeolho_ver.aspx?id=758

Elias, N. (1994). A sociedade dos indivíduos. Rio de Janeiro, RJ: Jorge Zahar. 
Fanon, F. (2008). Pele negra, máscaras brancas. Salvador, BA: Universidade Federal da Bahia.

Foucault, M. (2006). A hermenêutica do sujeito. São Paulo, SP: Martins Fontes.

Goldman, M. (1985). A construção ritual da pessoa. Revista Religião e Sociedade, 12(1), 22-54.

Goldman, M. (2015). Quinhentos anos de contato: Por uma teoria etnográfica da contramestiçagem. Mana, 21(3), 641-659. https://doi.org/10.1590/0104-93132015v21n3p641

Gomberg, E. (2011). Hospital de orixás: Encontros terapêuticos em um terreiro de candomblé. Salvador, BA: Universidade Federal da Bahia.

Guedes, S. L. (2003). Umbanda e loucura. In: G. Velho (Org.), Desvio e divergência (pp. 82-98). Rio de Janeiro, RJ: Jorge Zahar.

Jesus, F. S., Silva, J., \& Carmo, N. L. (2018). Implementação da lei 10.639: O olhar de um negro intelectual. Revista da $A B P N$, 10(Esp.), 135-158.

Kagame A. (1975). A percepção empírica do tempo e concepção da história do pensamento bantu. In: P. Ricoeur, As culturas e o tempo (pp. 102-105). Petrópolis, RJ: Vozes.

Kolá, A. (2005). Yorùbá diaspora. In: M. Ember, C. R. Ember, \& I. Skoggard (Orgs.), Encyclopedia of diasporas: Immigrant and refugee cultures around the world (pp. 211-222). New York, NY: Kluwer Academic.

Lancetti, A. (2006). Clinica peripatética. São Paulo, SP: Hucitec.

Lei n. 10.639, de 9 de janeiro de 2003. Altera a Lei n. 9.394, de 20 de dezembro de 1996, que estabelece as diretrizes e bases da educação nacional, para incluir no currículo oficial da Rede de Ensino a obrigatoriedade da temática “História e Cultura Afro-Brasileira”, e dá outras providências. Diário Oficial da União, 10 jan 2003. (era BRASIL.)

Lei n. 11.645, de 10 março de 2008. Altera a Lei n. 9.394, de 20 de dezembro de 1996, modificada pela Lei n. 10.639, de 9 de janeiro de 2003, que estabelece as diretrizes e bases da educação nacional, para incluir no currículo oficial da rede de ensino a obrigatoriedade da temática "História e Cultura Afro-Brasileira e Indígena”. Diário Oficial da União, 11 mar 2008. (era BRASIL.)

Mattoso, K. M. Q. (2016). Ser escravo no Brasil: Século XVI-XIX. Petrópolis, SP: Vozes.

Melo, A. (2014). 75\% dos escravos levados para o Brasil eram banto. Brasília, DF: Palmares Fundação Cultural. Recuperado de http://www.palmares.gov.br/?p=2889.

Mello, C. C. A. (2003). Obras de arte e conceitos: Cultura e antropologia do ponto de vista de um grupo afro-indígena do sul da Bahia (Disertação de mestrado). Universidade Federal do Rio de Janeiro, Rio de Janeiro, RJ, Brasil.

Moore, C. (2010). A África que incomoda: Sobre a problematização do legado africano no cotidiano brasileiro. Belo Horizonte, MG: Nandyala.

Nathan, T. (1995). Manifeste pour une psychopathologie sientifique. In: T. Nathan, \& I. Stangers, Médecins et sociers (pp. 09-112). Paris: Les Empêcheurs de Penser en Rond.

Nietzsche, F. (1995). Prólogo de Zaratustra. In: F. Nietzsche, Assim falava Zaratustra (pp. inicial-final). Rio de Janeiro, RJ: Bertrand Brasil.

Oliveira, R. J. (2017). A formação do psicólogo no contexto da diáspora africana. In: R. M. S. Oliveira, \& R. J. Oliveira, Dilemas da raça: Empoderamento e resistência (pp. 145-190). São Paulo, SP: Alameda.

Oliveira, M. R., \& Junges, J. R. (2012). Saúde mental e espiritualidade/religiosidade: A visão de psicólogos. Estudos de Psicologia (Natal), 17(3), 469-476. https://doi.org/10.1590/S1413-294X2012000300016

Opipari, C. (2009). Candomblé, imagens em movimento. São Paulo, SP: Universidade de São Paulo.

Pinto, V. (2014). A saúde no terreiro. Trabalho apresentado no Encontro de Subjetividade e Cultura Afro-brasileira, Niterói, RJ, Brasil, 1. Recuperado de https://www.youtube.com/watch?v=jI148SvCC7s\&t=5s.

Prandi, R. (2001). Mitologia dos orixás. São Paulo SP: Companhia das Letras.

Rede Nacional de Religiões Afro-Brasileiras - Renafro. (2013). O Cuidar no terreiro. Brasília, DF: o autor. Recuperado de http://www.youtube.com/watch?v=oMDGTHQe9Ao.

Resolução CFP № 18/2002, de 19 de dezembro de 2002. Estabelece normas de atuação para os psicólogos em relação ao preconceito e à discriminação racial. Brasília, DF: Recuperado de https://site.cfp.org.br/wp-content/ uploads/2002/12/resolucao2002_18.PDF 
Rey, F. G. (2004). O social na psicologia e a psicologia social: A emergência do sujeito. Petrópolis, RJ:Vozes.

Santos, A. B. (2015). Colonização, quilombos: Modos e significados. Brasília, DF: Universidade Federal de Brasília.

Santos, J. E. (1998). Os nagô e a morte. Petrópolis, RJ: Vozes.

Silva, J. (2017). Negritude e universidade: Evidenciando questões relacionadas ao ingresso e aos projetos curriculares. Revista Contemporânea de Educação, 12(23), 193-197. https://doi.org/10.20500/rce.v12i23.9952

Stengers, I. (2013). Cosmopolitiques: Civilizer les pratiques modernes. In:W. James, \& I. Stangers, Une autre science est possible (pp. 113-144). Paris: Découverte.

Templs, R. P. P. (1948). La philosophie bantue. Paris: Pésence Africaine.

Velho, G. (1997). Relações entre antropologia e psiquiatria. In: G. Velho, Individualismo e cultura: Notas para uma antropologia da sociedade contemporânea (pp. 97-106). Rio de Janeiro, RJ: Zahar.

\section{Abrahao de Oliveira Santos}

Professor Associado do Departamento de Psicologia da Universidade Federal Fluminense (UFF), Niterói - RJ. Brasil. E-mail: abrahaosantos@hotmail.com

(iD https://orcid.org/0000-0001-7741-3020

Endereço para envio de correspondência:

Rua Buarque de Macedo, 32/603, Flamengo, Rio de Janeiro - RJ

CEP: 22220-030

Recebido 01/04/2019

Aceito 06/05/2019

Received 04/01/2019

Approved 05/06/2019

Recibido 01/04/2019

Aceptado 06/05/2019

Como citar: Santos, A. O. (2019). O enegrecimento da Psicologia: Indicações para a formação profissional.

Psicologia: Ciência e Profissão, 39(n.spe)., 159-171. https:// doi.org/10.1590/1982-3703003222113

How to cite: Santos, A. O. (2019). The blackening of Psychology: Indications for vocational training. Psicologia:

Ciência e Profissão, 39(n.spe), 159-171. https://doi.org/10.1590/1982-3703003222113

Cómo citar: Santos, A. O. (2019). El ennegrecimiento de la Psicología: Indicaciones para la formación profesional. Psicologia: Ciência e Profissão, 39(n.spe), 159-171. https://doi.org/10.1590/1982-3703003222113 